University of Nebraska - Lincoln

DigitalCommons@University of Nebraska - Lincoln

Faculty Publications: Department of Entomology

1988

\title{
Response of Screwworms (Diptera: Calliphoridae) to Changes in the concentration of Blood, Egg, and Milk in the Larval Diet
}

David B. Taylor

University of Nebraska-Lincoln, dave.taylor@ars.usda.gov

Follow this and additional works at: https://digitalcommons.unl.edu/entomologyfacpub

Part of the Entomology Commons

Taylor, David B., "Response of Screwworms (Diptera: Calliphoridae) to Changes in the concentration of Blood, Egg, and Milk in the Larval Diet" (1988). Faculty Publications: Department of Entomology. 211. https://digitalcommons.unl.edu/entomologyfacpub/211

This Article is brought to you for free and open access by the Entomology, Department of at DigitalCommons@University of Nebraska - Lincoln. It has been accepted for inclusion in Faculty Publications: Department of Entomology by an authorized administrator of DigitalCommons@University of Nebraska - Lincoln. 


\title{
Response of Screwworms (Diptera: Calliphoridae) to Changes in the Concentration of Blood, Egg, and Milk in the Larval Diet
}

\author{
DAVID B. TAYLOR
}

Screwworm Research, Agricultural Research Service, U.S. Department of Agriculture, Tuxtla Gutierrez, Chiapas, Mexico

\begin{abstract}
J. Econ. Entomol. 81(2): 562-567 (1988)
ABSTRACT Larvae of screwworm, Cochliomyia hominivorax (Coquerel), were reared on diets with varying concentrations of whole dried bovine blood, whole dried egg, and nonfat dried milk. Pupal weight, egg to pupal survival, adult emergence, sex ratio, fecundity, and fertility were significantly affected by one or more of the dietary components. Curvilinear models for the effect of dietary component concentration on life history parameters were derived by multiple regression. Most models resulted in bell-shaped curves that were used to calculate optimal diet component concentrations. Biomass, survival, emergence, and fecundity were maximized at $6 \%$ blood, $5 \% \mathrm{egg}$, and $1.3 \%$ milk.
\end{abstract}

KEY WORDS Insecta, screwworm, larval rearing, larval nutrition

CONTROL AND ERADICATION efforts for screwworm, Cochliomyia hominivorax (Coquerel), in Mexico and Central America are dependant upon the mass production of hundreds of millions of screwworm flies per week for sterilization and release. Cost of diet ingredients for this program is in excess of $\$ 50,000$ per wk. Optimizing this diet could result in large monetary savings for the eradication program as well as improve the competitiveness of the released sterile flies.

A liquid diet developed by Gingrich et al. (1971) and currently used for the mass production of screwworms originally consisted of whole dried chicken egg, whole dried bovine blood, calf suckle (a milk substitute), and dried cottage cheese supplemented with sucrose. Brown \& Snow (1979) modified this diet by eliminating dried cottage cheese and increasing the amount of whole dried blood. In both studies, larval weight was the sole criterion for determining the quality of the test diets; such factors as larval survival, adult emergence, and fecundity were not considered.

A diet consisting of $7 \%$ whole dried blood, $3 \%$ whole dried egg, and $3 \%$ nonfat dried milk (Brown \& Snow 1979) has been used, with minor modifications, for screwworm mass production during the past $6 \mathrm{yr}$. Although practical experience indicated that this diet was optimal, no quantitative studies have been done to demonstrate its efficacy. Effects of varying concentrations of the three primary larval diet ingredients-whole dried bovine blood, whole dried chicken egg, and nonfat dried milkon pupal weight, egg to pupal survival, adult emergence, sex ratio, fecundity, and fertility of screwworms were evaluated in this study.

\section{Materials and Methods}

Rearing techniques used for this study were similar to those used for a gelled diet (Water-Lock
G-400 ${ }^{1}$ ) by Taylor \& Mangan (1987). A 1.2\% gelled diet was used throughout this study. Each larval pan ( 19 by 16 by $9 \mathrm{~cm}$ deep) received $100 \mathrm{mg}$ of eggs (ca. 2,700 eggs) from the ARS-USDA line of the VF-84 strain of screwworms. Freshly oviposited eggs were placed in Petri dishes (9 cm diameter) with a small amount (ca. $5 \mathrm{~g}$ ) of fresh horse meat on day 0 . Upon eclosion, the larvae began feeding on the meat. Larvae, along with the meat, were transferred to a rearing pan with 0.5 liter of diet the following day (day 1). Pans were placed in an open water bath maintained at $39^{\circ} \mathrm{C}$. Larvae were not given new diet on day 2 , but were fed 0.5 liter on day 3 , and 1 liter on day 4. Pans were removed from the heated water bath and placed on trays containing a layer of sawdust when mature larvae were observed on the gel surface (usually day 5). Larvae crawled off the media (crawl-off) and dropped into the sawdust for pupation. Five days after the initiation of crawl-off, larval pans were removed from the sawdust trays and discarded. Pupae were sifted from the sawdust the following day. Total volume, weight of $10 \mathrm{ml}$, and number of pupae in the $10-\mathrm{ml}$ sample were recorded. The 10-ml sample (ca. 80-250 pupae) was then placed in a small closed cup and used to determine adult emergence and sex ratio. Pupae from each pan (50 $\mathrm{ml}$ ) were placed in a small cage ( 15 by 30 by 12 $\mathrm{cm}$ ). Adults were provided water and honey ad lib. and induced to oviposit on a piece of fresh horse meat $8 \mathrm{~d}$ after initial adult emergence. Weight of the eggs oviposited (fecundity) and percentage eclosion (fertility) were recorded.

Six tests were run to examine each of the three components in reduced and normal nutrient backgrounds. The reduced nutrient diet was used to test

${ }^{1}$ This article reports the results of research only. Mention of a proprietary product does not constitute an endorsement or recommendation for its use by the U.S. Department of Agriculture. 
the effect of each component on larvae under nutritional stress. The normal nutrient diet was used to determine the effects of varying the concentrations of each component under conditions similar to those experienced in mass rearing. All diets were expressed as grams of blood/egg/milk per $100 \mathrm{ml}$ of water (parts per hundred of water abbreviated ppc). Thus a diet expressed as 7:1:3 consists of $7 \mathrm{~g}$ blood, $1 \mathrm{~g}$ egg, $3 \mathrm{~g}$ milk, and $1.2 \mathrm{~g}$ gelling agent per $100 \mathrm{ml}$ of water. Formalin $(1.2 \mathrm{ml} /$ liter of water) was added to all diets to retard putrefaction.

Each dietary component concentration was varied individually while the other two were held constant. Diets examined were $0,3,5,7,9,11,13$, and 15:1:1 $(x: 1: 1) ; 0,3,5,7,9,11,13$, and 15:5:5 $(x: 5: 5) ; 2: 0,1,3,5,7$, and $9: 1(2: x: 1) ; 7: 0,1,3,5$, 7 , and $9: 3(7: x: 3) ; 2: 1: 0,1,3,5,7$, and $9(2: 1: x)$; and $7: 3: 0,1,3,5,7$, and $9(7: 3: x)$. Each diet was replicated four times. Dietary components-blood, egg, and milk-from a single shipment or lot were used for each test.

Analysis of variance (ANOVA) (Wilkinson 1985, 181-261, MGLH procedure) was used to test for linear and nonlinear effects of component concentrations on screwworm life history parameters. Linear regression was used to detect linear trends (Wilkinson 1985, 181-261, MGLH procedure). Curvilinear models of the form, $c+b x+a x^{2}(x=$ grams of component $/ 100 \mathrm{ml}$ of water) were initially tested for each parameter. Terms were excluded from the model step-wise $(P>0.05)$. Pearson correlation coefficients were calculated for the life history parameters (Wilkinson 1985, 173-179, CORR procedure). Calculations were performed using the SYSTAT statistical package (version 2) (Wilkinson 1985) on an IBM-PC equipped with an 8087 math co-processor.

\section{Results}

Blood. Blood concentration significantly affected pupal weight, number of pupae per pan, and percentage of adult emergence when screwworm larvae were fed a diet with reduced concentrations of egg and milk (Table 1). The 0- and 15-ppc blood groups were excluded from the analysis of fertility and fecundity because too few pupae were recovered to complete oviposition observations. The 0 -ppc blood group was excluded from the analysis of sex ratio (percentage female) because only one fly developed to adulthood. The effect of blood concentration on sex ratio and egg fertility was marginally significant. On the low nutrient diet, fecundity of flies was uniformly low, irrespective of blood concentration. The effect of blood concentration on pupal weight, number of pupae, percentage adult emergence, fecundity, and fertility could be explained by quadratic, curvilinear models (Fig. 1; Table 1). Each model represented a bellshaped curve that could be optimized within the test range (Table 1). Even when screwworm larvae were under nutrient stress, growth and survival were inhibited by blood concentrations $>8-9$ ppc.

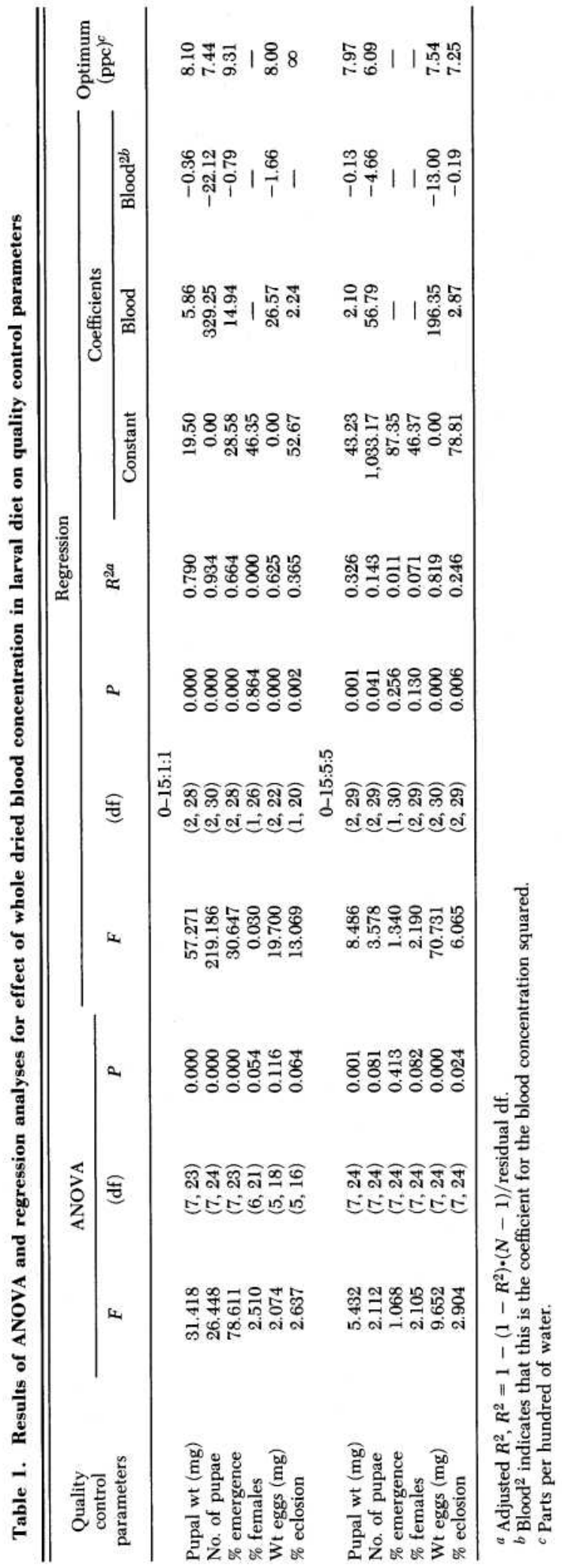



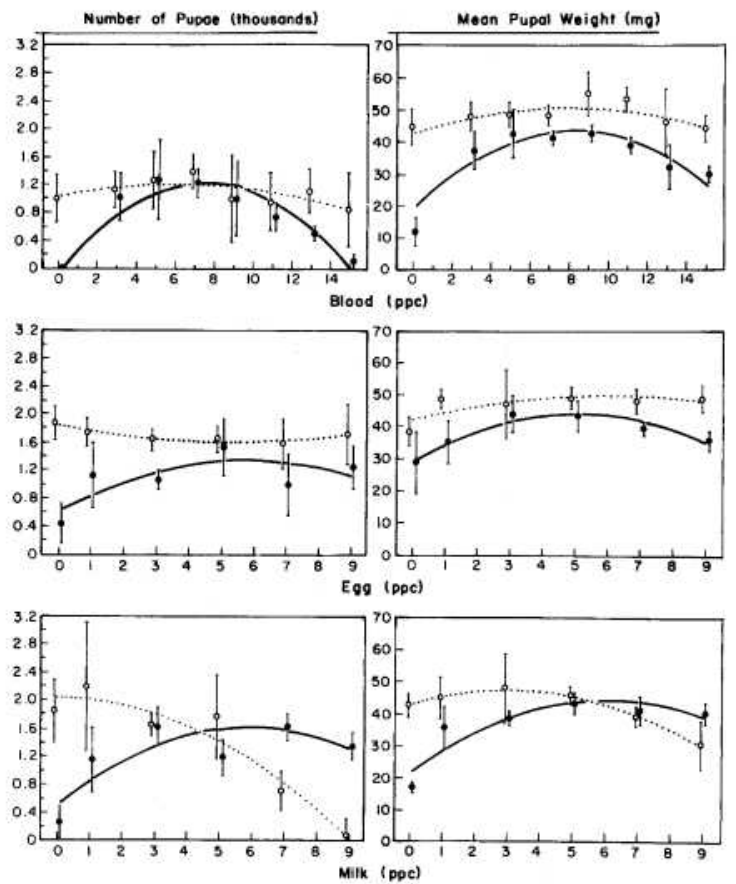

Fig. 1. Effect of dietary component concentration on mean pupal weight and number of pupae recovered from $100 \mathrm{mg}$ of eggs. Fitted curves represent the best fit curvilinear models. Symbols represent treatment means, and vertical lines represent $95 \%$ confidence limits. Solid lines and circles represent low nutrient diets; broken lines and open circles represent high nutrient diets. Diet concentrations are presented in parts per $100 \mathrm{ml}$ of water (ppc).

Blood concentrations had a reduced effect on the parameters examined when the concentrations of egg and milk were increased to 5 ppc each. Blood concentration significantly affected pupal weight, fecundity, and fertility. The effect of blood concentration on the number of pupae per pan and sex ratio was marginally significant. Optimal concentrations of blood for the four parameters with significant curvilinear regression models ranged between 6 and 8 ppc. Pupal weight had the highest optimal concentration, and number of pupae per pan had the lowest. Because these two parameters were considered most important to the mass production and eradication program, a blood concentration optimizing them both was desirable. Biomass of pupae produced per pan (mean pupal weight $\times$ number of pupae per pan) incorporated both terms and was therefore used to access diet quality. A value of 6.9 ppc of blood yielded maximum biomass per pan.

Egg. When screwworm larvae were fed a diet with reduced concentrations of blood and milk, egg significantly affected mean pupal weight, number of pupae per pan, and fecundity (Table 2). As with blood, the response of each parameter to egg concentration fit a quadratic, curvilinear model. Each model represented a bell-shaped curve with the optimum egg concentration given in Table 2. Egg concentration had less effect on all of the parameters except fecundity than did blood concentration (Fig. 1; Table 2). Female fecundity rose steeply in relation to egg concentration on the low nutrient diet. The effects of egg concentration were less when larvae were fed a diet consisting of $7 \mathrm{ppc}$ blood and 3 ppc milk. Under these conditions, egg concentration significantly affected pupal weight, sex ratio, and fertility. The optimal concentration of egg for pupal weight was 5.99 ppc. Because egg concentrations did not significantly affect the number of pupae per pan, this figure also optimized biomass. Although the sex ratio varied significantly with respect to concentration of egg in the larval diet, no curvilinear trend was observed. The 5-, 7-, and 9-ppc egg groups had unexpectedly low eclosion (ca. 25\%). Low eclosion at high concentrations of egg was not observed in subsequent tests. This effect was probably due to an unidentified problem in egg preparation or incubation, and not a direct result of egg concentration in the larval diet.

Milk. Concentration of milk in the larval diet had a greater effect on the parameters examined than the concentration of egg. On the low nutrient diet, milk concentration significantly affected pupal weight, number of pupae, adult emergence, and sex ratio (Table 3 ). The effect of milk concentration on fecundity was marginally significant. The optimal concentrations of milk ranged between 5 and $6 \mathrm{ppc}$ on the low nutrient diet. The effects of milk concentration on the high nutrient diet were quite different from those observed on the low nutrient diet. All of the parameters, with the exception of sex ratio, varied significantly with respect to milk concentration. Curvilinear models for pupal weight and fertility resulted in optimal milk concentrations of 3.13 and $3.62 \mathrm{ppc}$, respectively. Curvilinear models for number of pupae per pan, percentage adult emergence, and fecundity optimized to 0 ppc milk. The curvilinear models for pupal weight, number of pupae per pan, and fecundity on the high nutrient diets intersected those of the low nutrient diets between 4 and 7 ppc of milk (Fig. 1; Table 3). The optimal concentration of milk in the larval diet (calculated as for blood) was 1.5 ppc.

Correlation of Parameters. A correlation analysis was performed to determine the interrelationships of the life history parameters examined. Fertility (percentage egg eclosion) was excluded from this analysis because of the excessive number of missing values due to reduced fecundity. Fecundity (milligrams of eggs per cage) was assigned a value of zero for those groups with too few pupae. The matrix of Pearson correlation coefficients for the combined data of all of the diet tests is presented in Table 4. Pupal weight was positively correlated with survival, adult emergence, and fecundity, which indicates that competition did not significantly affect those parameters. Pupal weight 
Table 2. Results of ANOVA and regression analyses for effect of whole dried egg concentration in larval diet on quality control parameters

\begin{tabular}{|c|c|c|c|c|c|c|c|c|c|c|c|}
\hline \multirow{3}{*}{$\begin{array}{l}\text { Quality } \\
\text { control } \\
\text { parameters }\end{array}$} & \multicolumn{3}{|c|}{ ANOVA } & \multicolumn{7}{|c|}{ Regression } & \multirow{3}{*}{$\underset{(\mathrm{ppc})^{c}}{\text { Optimum }}$} \\
\hline & \multirow{2}{*}{$F$} & \multirow{2}{*}{ (df) } & \multirow{2}{*}{$P$} & \multirow{2}{*}{$F$} & \multirow{2}{*}{ (df) } & \multirow{2}{*}{$P$} & \multirow{2}{*}{$R^{2 a}$} & \multicolumn{3}{|c|}{ Coefficients } & \\
\hline & & & & & & & & Constant & Egg & $\mathrm{Egg}^{2 b}$ & \\
\hline \multicolumn{12}{|c|}{$2: 0-9: 1$} \\
\hline Pupal wt (mg) & 11.679 & $(5,18)$ & 0.000 & 25.523 & $(2,21)$ & 0.000 & 0.681 & 29.84 & 5.79 & -0.58 & 4.97 \\
\hline No. of pupae & 11.954 & $(5,18)$ & 0.000 & 8.123 & $(2,21)$ & 0.002 & 0.382 & 639.63 & 244.17 & -21.18 & 5.76 \\
\hline$\%$ emergence & 1.362 & $(5,18)$ & 0.284 & 3.292 & $(2,21)$ & 0.057 & 0.166 & 92.32 & 1.42 & -0.18 & 3.88 \\
\hline$\%$ females & 2.342 & $(5,18)$ & 0.084 & 3.491 & $(1,22)$ & 0.075 & 0.098 & 52.42 & -0.60 & - & 4.03 \\
\hline Wt eggs (mg) & 7.065 & $(5,18)$ & 0.001 & 39.527 & $(2,22)$ & 0.000 & 0.772 & 0.00 & 248.77 & -24.88 & 4.98 \\
\hline$\%$ eclosion & 0.737 & $(5,14)$ & 0.608 & 0.215 & $(2,17)$ & 0.809 & 0.000 & 79.03 & - & - & - \\
\hline \multicolumn{12}{|c|}{$7: 0-9: 3$} \\
\hline Pupal wt (mg) & 6.356 & $(5,18)$ & 0.001 & 6.126 & $(2,21)$ & 0.008 & 0.308 & 42.15 & 2.66 & -0.22 & 5.99 \\
\hline No. of pupae & 1.810 & $(5,18)$ & 0.162 & 4.664 & $(2,21)$ & 0.021 & 0.242 & $1,867.11$ & -95.52 & 8.51 & $\infty$ \\
\hline$\%$ emergence & 2.074 & $(5,18)$ & 0.116 & 0.564 & $(2,21)$ & 0.577 & 0.000 & 94.70 & - & - & - \\
\hline$\%$ females & 3.912 & $(5,18)$ & 0.014 & 1.015 & $(2,21)$ & 0.379 & 0.001 & 49.10 & - & - & - \\
\hline Wt eggs (mg) & 1.377 & $(5,18)$ & 0.279 & 3.592 & $(1,22)$ & 0.071 & 0.101 & 445.12 & - & - & - \\
\hline$\%$ eclosion & 201.841 & $(5,18)$ & 0.000 & 39.888 & $(1,22)$ & 0.000 & 0.628 & 84.20 & -6.40 & - & 0.00 \\
\hline
\end{tabular}

${ }^{a}$ Adjusted $R^{2}, R^{2}=1-\left(1-R^{2}\right) \cdot(N-1) /$ residual df.

${ }^{b} \mathrm{Egg}^{2}$ indicates that this is the coefficient for the egg concentration squared.

${ }^{c}$ Parts per hundred of water.

Table 3. Results of ANOVA and regression analyses for effeet of nonfat dried milk concentration in larval diet on quality control parameters

\begin{tabular}{|c|c|c|c|c|c|c|c|c|c|c|c|}
\hline \multirow{3}{*}{$\begin{array}{l}\text { Quality } \\
\text { control } \\
\text { parameters }\end{array}$} & \multicolumn{3}{|c|}{ ANOVA } & \multicolumn{7}{|c|}{ Regression } & \multirow{3}{*}{$\underset{(p p c)^{c}}{\text { Optimum }}$} \\
\hline & \multirow{2}{*}{$F$} & \multirow{2}{*}{ (df) } & \multirow{2}{*}{$P$} & \multirow{2}{*}{$F$} & \multirow{2}{*}{ (df) } & \multirow{2}{*}{$P$} & \multirow{2}{*}{$R^{2 a}$} & \multicolumn{3}{|c|}{ Coefficients } & \\
\hline & & & & & & & & Constant & Milk & Milk $^{2 b}$ & \\
\hline & & & & & \multicolumn{2}{|c|}{$2: 1: 0-9$} & & & & & ' \\
\hline Pupal wt (mg) & 76.597 & $(5,18)$ & 0.000 & 38.857 & $(2,21)$ & 0.000 & 0.767 & 21.48 & 7.59 & -0.63 & 5.98 \\
\hline No. of pupae & 39.093 & $(5,18)$ & 0.000 & 17.987 & $(2,21)$ & 0.000 & 0.596 & 515.6 & 370.23 & -31.60 & 5.86 \\
\hline$\%$ emergence & 15.571 & $(5,18)$ & 0.000 & 8.888 & $(2,21)$ & 0.002 & 0.407 & 77.98 & 7.35 & -0.69 & 5.35 \\
\hline$\%$ females & 4.928 & $(5,18)$ & 0.005 & 6.191 & $(1,22)$ & 0.021 & 0.184 & 55.04 & -0.94 & - & 5.36 \\
\hline Wt eggs (mg) & 2.425 & $(5,18)$ & 0.076 & 31.187 & $(2,22)$ & 0.000 & 0.727 & 0.00 & 96.68 & -7.98 & 6.06 \\
\hline \multicolumn{12}{|c|}{$7: 3: 0-9$} \\
\hline Pupal wt (mg) & 11.218 & $(5,18)$ & 0.000 & 32.102 & $(2,21)$ & 0.000 & 0.730 & 42.31 & 3.11 & -0.50 & 3.13 \\
\hline No. of pupae & 26.666 & $(5,18)$ & 0.000 & 98.876 & $(1,22)$ & 0.000 & 0.810 & $2,038.89$ & - & -24.09 & 0.00 \\
\hline$\%$ emergence & 9.250 & $(5,18)$ & 0.000 & 17.668 & $(1,22)$ & 0.000 & 0.420 & 98.40 & - & -0.40 & 0.00 \\
\hline$\%$ females & 1.765 & $(5,18)$ & 0.171 & 4.235 & $(2,21)$ & 0.029 & 0.220 & 52.30 & -2.40 & 0.30 & 1.11 \\
\hline Wt eggs (mg) & 11.747 & $(5,18)$ & 0.000 & 67.703 & $(1,22)$ & 0.000 & 0.744 & 875.63 & -91.50 & - & 0.00 \\
\hline$\%$ eclosion & 69.829 & $(5,15)$ & 0.000 & 5.691 & $(2,18)$ & 0.012 & 0.319 & 73.30 & 5.80 & -0.80 & 3.62 \\
\hline
\end{tabular}

a Adjusted $R^{2}, R^{2}=1-\left(1-R^{2}\right) \cdot(N-1) /$ residual df.

${ }^{b}$ Milk $^{2}$ indicates that this is the coefficient for the blood concentration squared.

${ }^{c}$ Parts per hundred of water. 
Table 4. Matrix of Pearson's correlation coefficients for pooled data from all diet tests, ${ }^{a} \mathrm{n}=160$

\begin{tabular}{|c|c|c|c|c|c|}
\hline & Pupal wt & No. of pupae & Emergence (\%) & Females (\%) & $\begin{array}{c}\text { Fecundity/ } \\
\text { wt eggs }\end{array}$ \\
\hline Pupal wt & 1.00 & & & & \\
\hline No. of pupae & $0.539^{b}$ & 1.000 & & & \\
\hline Emergence & $0.552^{b}$ & $0.539^{b}$ & 1.000 & & \\
\hline$\%$ females & $-0.418^{b}$ & -0.123 & $-0.165^{c}$ & 1.000 & \\
\hline Fecundity & $0.586^{b}$ & $0.466^{b}$ & $0.306^{b}$ & $-0.178^{c}$ & 1.000 \\
\hline
\end{tabular}

a Values range from -1 to 1 . Negative values indicate a negative correlation between parameters and positive values indicate a positive correlation. A value of zero indicates the two parameters are not correlated.

${ }^{b} r<>0, P<0.01$.

${ }^{c} r<>0, P<0.05$.

was negatively correlated with percentage females; that is, higher pupal weights favored males.

\section{Discussion}

Pupal weight, survival, and fecundity were the parameters most affected by concentrations of blood, egg, and milk in screwworm diets. These were also the three most critical parameters for screwworm mass production. Blood concentrations over ca. 8 ppc were deleterious to screwworm growth even when larvae were under diet stress. Brown \& Snow (1979) indicated that acceptable larvae (Alley \& Hightower 1966, Hightower et al. 1972) (>60 mg) could be produced on diets with 9-12\% blood; however, Brown \& Snow (1979) did not examine survival. A $60-\mathrm{mg}$ larva corresponded to a 40.5-mg pupa (5 d after pupation) (unpublished data). Based on the models derived in this study, 51.6-mg pupae would be produced with $9 \%$ blood, and 49.7-mg pupae would be produced with $12 \%$ blood. These findings agreed with those of Brown \& Snow (1979). However, at $9 \%$ blood, production would be reduced by $3.5 \%$, and at $12 \%$ blood, production would be reduced by $13.9 \%$.

Effects of blood and egg concentrations were more pronounced on low nutrient diets. This difference was expected at the lower concentrations of the test components, where the total nutrient content of the diet was low. However, the exaggerated deleterious effects of high blood and egg concentrations were not expected. The number of pupae was approximately equal in the 5-, 7-, and 9 -ppc blood groups on the high and low nutrient diets. However, significantly fewer pupae were recovered from the 15:1:1 group than the 15:5:5 group. These results indicated that either total protein content or high milk concentration may buffer the toxic effects of high blood and egg concentrations on screwworm larvae. Response of screwworm larvae to high concentrations of milk was different than their response to high concentrations of blood or egg. Pupal weight, survival, and fecundity were all better on the 2:1:9 diet than on the $7: 3: 9$ diet. These data indicate a negative interaction between high concentrations of milk and one of the following: high total protein, high blood, or high egg concentrations.
Concentration of egg in the larval diet appeared to be especially important for fecundity. On the low nutrient diet, fecundity was uniformly low at all concentrations of blood and milk, $<300 \mathrm{mg}$ of eggs per cage. Conversely, after adding egg, fecundity rose rapidly from no eggs at all at $0 \mathrm{ppc}$ of egg to a mean of $776 \mathrm{mg}$ of eggs per cage at 3 ppc of egg. Weight of eggs oviposited did not differ significantly between the high and low nutrient diets when the egg concentration was above 3 ppc.

Although pupal weight increased slightly with the addition of milk up to 3 ppc, milk was clearly deleterious to survival and fecundity of screwworm larvae. These data agreed with those of Gingrich et al. (1971), who reported that milk was not a satisfactory substitute for egg and that its high carbohydrate content was deleterious to screwworm larvae. Milk was originally added to the screwworm larval diet to replace calf suckle and has been used in concentrations as high as $5 \%$. Results of this study indicate that reducing the concentration of milk in the screwworm diet to $<1.5 \mathrm{ppc}$ would improve survival, adult emergence, and fecundity with no significant effect on pupal weight.

Component concentrations of $6.9 \mathrm{ppc}$ blood, 6.0 ppc egg, and 1.5 ppc milk were optimal under the conditions of this study. To directly compare this proportion to the diet formulation currently used for mass production of screwworms, it must be transformed to percentage total weight. The optimal diet formulation $(6.9 \mathrm{ppc}$ blood, $6.0 \mathrm{ppc}$ egg, and $1.5 \mathrm{ppc}$ milk) is equivalent to a diet of $6 \%$ blood, $5.2 \%$ egg, and $1.3 \%$ milk. This diet had approximately the same total nutrient content as the $7 \%$ blood, $3 \%$ egg, and $3 \%$ milk diet currently used for screwworm mass production- 12.5 versus $13 \%$. The primary difference is the partial replacement of blood and milk with egg.

Techniques outlined in this paper could be used to bioassay the quality of incoming dietary products. Quality and composition of dietary ingredients vary between lots. When these tests were repeated on a shipment of blood thought to be of low quality, survival decreased linearly with blood concentration. To maintain an optimal diet, each lot of blood, egg, and milk should be tested to determine quality and optimal concentration. Adoption of this system would minimize expenditures for diet components and optimize fly quality. 


\section{Acknowledgment}

I thank D. L. Bailey, R. L. Harris, and N. C. Leppla for their helpful suggestions and critical review of the manuscript. Fig. 1 was prepared by L. Leiser.

\section{References Cited}

Alley, D. A. \& B. G. Hightower. 1966. Mating behavior of the screwworm fly as affected by differences in strain and size. J. Econ. Entomol. 59: 1499-1502.

Brown, H. E. \& J. W. Snow. 1979. Screwworms (Diptera: Calliphoridae): a new liquid medium for rearing screwworm larvae. J. Med. Entomol. 16: 29-32.

Gingrich, R. E., A. J. Graham \& B. G. Hightower. 1971. Media containing liquefied nutrients for mass- rearing larvae of the screwworm. J. Econ. Entomol. 64: 678-683.

Hightower, B. G., G. E. Spates, Jr., \& J. J. Gareia. 1972. Growth and critical size at pupation for larvae of the screwworm developing in fresh wounds. J. Econ. Entomol. 65: 1349-1352.

Taylor, D. B. \& R. L. Mangan. 1987. Comparison of gelled and meat diets for rearing screwworm, Cochliomyia hominivorax (Diptera: Calliphoridae), larvae. J. Econ. Entomol. 80: 427-432

Wilkinson, L. 1985. SYSTAT, the system for statistics, version 2. SYSTAT, Evanston, Ill.

Received for publication 20 February 1987; accepted 20 October 1987. 